\title{
Alejandro Ruiz-Argüelles 1952-2019
}

\author{
Mario C. Salinas-Carmona* \\ Department of Immunology Service, School of Medicine, "Dr. José E. González" University Hospital, Autonomous University of Nuevo Leon, Nuevo \\ Leon, Mexico
}

Dr. Alejandro was born in 1952 in the heart of a prestigious medical family. He obtained his medical degree at the Autonomous University of San Luis Potosí, in Mexico, and continued his training in Mexico City at the Salvador Zubiran National Institute of Nutrition (INNSZ by its Spanish acronym), working in research at the Rheumatology Department under the supervision of Dr. Donato Alarcón Segovia. He developed a close friendship with our mutual friend, Dr. Mario Alberto Garza Elizondo, who was completing his residency in rheumatology. During that time, Alejandro published an article in the journal Nature that caused a controversy among immunologists around the world. Alejandro completed his training in immunology at the School of Medicine of the National Autonomous University of Mexico (UNAM by its Spanish acronym); subsequently. He studied his postgraduate program, also in immunology, at the School of Medicine of the University of Minnesota. Alejandro's increasing interest in the field of biomedical research and access to flow cytometry equipment played a major role in his professional life. He was acknowledged throughout America due to his participation in conventions and courses, making him a world-class expert in biomedical applications of flow cytometry, and he achieved recognition as vice-president of the scientific division at the Federation for Clinical Chemistry. His multiple scientific publications allowed him national recognition by Mexico's National System of Researchers (SNI by its Spanish acronym), where he moved upward to its top levels.
With all his experience in the field of biomedicine and flow cytometry as a fundamental tool in scientific research, and having multiple honors to his name, like being a part of forming human resources by directing graduate theses, he was received as an associate member, and later as a sitting member, of the National Academy of Medicine.

Alejandro did not work at public institutions after he established himself as the Director of the Clinical Laboratories of Puebla, a prestigious private institution where he was in charge of having up-to-date daily laboratory results not only from Puebla but also from the entire country. In addition, Alejandro always sought the technological advances that in the US and Europe and immediately put them at the service of the community.

His joyful and cheerful nature, as well as his willingness to collaborate and work as a team, earned him the sympathy of the national researchers' community, where he participated in several national commissions evaluating requests for economic support at the National Council for Science and Technology (CONACYT by its Spanish acronym).

In the year 2000, I had the privilege of collaborating with Alejandro to write the chapter "Immunological techniques used in the diagnosis and prognosis of human diseases" of the book titled "Immunology in Health and Sickness" published by Panamericana, which had already had three reprints and a $2^{\text {nd }}$ edition. In 2007, as a result of a series of conferences on "How to publish a scientific article" conducted in Monterrey,

\section{Correspondence:}

*Mario C. Salinas-Carmona

E-mail: mario.salinas@uanl.mx
Available online: $17-03-2020$

Date of reception: 05-02-2020

Date of acceptance: 10-02-2020 DOI: 10.24875/RMU.M20000039
Medicina Universitaria. 2020;22(1):44-45 www.medicinauniversitaria.org (http://creativecommons.org/licenses/by-nc-nd/4.0/). 
Mexico, and again due to his enthusiastic, participative, and collaborative nature, we accomplished the edition of a new book titled "How to write and publish a scientific article" under the supervision and edition of Dr. David Gómez Almaguer and the collaboration of physicians Ruy Pérez Tamayo, Rubén Lisker, Guillermo Ruiz-Argüelles, Hugo Barrera, Luis Llorente, Jose Carlos Jaime, Mario César Salinas Carmona, researcher's, and other collaborators.
Alejandro formed an ample and solid academic and professional reputation in very little time, as well as great friends. He would always stimulate us with his extensive knowledge of culture and personal mastery of English and Spanish, his great sense of humor, and his contagious happiness. His friends will never forget him.

Rest in peace, great friend, scientist and renowned professional, and pioneer in the use of flow cytometry in specialized clinical work. 